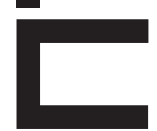

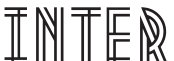

\title{
A IMPORTÂNCIA DA SEMIÓTICA NA PUBLICIDADE PARA A PROJEÇÃO DOS SIGNIFICADOS: UMA ANÁLISE DO ANÚNCIO MITSUBISHI PAJERO FULL
}

Ítalo Jorge Menezes Medeiros ${ }^{1}$

Talita de Azevedo Déda

\section{RESUMO}

Este artigo se destina a explicar a importância dos estudos semióticos na publicidade; tendo como referência os teóricos, Algirdas Julien Greimas, Charles Pierce, Roland Barthes e Martine Joly para um melhor entendimento dos conceitos que envolvem, desde as premissas básicas à semiótica da imagem, fundamental no ramo publicitário, tendo como objeto de análise o anúncio da Mitsubishi Pajero Full, com o objetivo de perceber por meio da semiótica as relações sígnicas e a produção de sentido engendrada na mensagem publicitária.

\section{PALAVRAS-CHAVE}

Semiótica. Publicidade. Signos. 


\section{ABSTRACT}

This article is intended to explain the importance of semiotic studies in advertising, having as reference the theorists Algirdas Julien Greimas, Charles Pierce, Roland Barthes and Martine Joly for a better understanding of the concepts involved, since the basic premises to semiotic of the image, fundamental in advertising industry, having as analysis' object the announcement of Mitsubishi Pajero Full, aiming to perceive through the semiotic sign relations and the production of meaning engendered in the advertisement.

\section{KEYWORDS}

Semiotic. Adversiting. Signs.

\section{RESUMEN}

Este artículo tiene la intención de explicar la importancia de los estudios semióticos en la publicidad, con referencia a los teóricos, Algirdas Julien Greimas, Charles Pierce, Roland Barthes y Martine Joly para una mejor comprensión de los conceptos involucrados, ya que los supuestos básicos de la semiótica de la imagen, fundamental en la industria de la publicidad, que tiene como objeto de análisis el anuncio de Mitsubishi Pajero Full, con el objetivo de realizar a través de las relaciones de signo semiótico y la producción de significado engendra en el anuncio.

\section{PALABRAS CLAVE}

Semiótica. Publicidade. Signos.

\section{INTRODUÇ̃̃O}

Há muitos estudos sobre a comunicação humana e sobre como os indivíduos de uma mesma sociedade interagem e comunicam entre si, através de desenhos, ideogramas, algarismos, idiomas, fala, entre outros. Porém, as análises sobre a significação e produção de sentido gerados na mensagem e o efeito que o discurso pode gerar no receptor, enquanto ações comunicativas e de linguagens ainda são recentes. Esses estudos ficam a cargo da Semiótica, sendo "conhecida como uma ciência dos signos, da significação e da cultura no século XX" (SANTAELLA, 2002, p. 11) que não só investiga a relação entre significantes e o seu significado, como também se apropria da linguística para fundamentar o modo como interagimos no mundo.

A Semiótica é a ciência que tem por objeto de investigação todas as linguagens possíveis, ou seja, que tem por objetivo o exame dos modos de constituição de todo e qualquer fenômeno como fenômeno de produção de significação e de sentido (SANTAELLA, 2005, p. 13).

A este ponto de vista, Santaella (2005) ressalta que a semiótica não pode ser considerada como uma ciência pronta e acabada, mas como "algo nascendo e em processo de crescimento. Esse algo é uma ciência, um território do saber e do conhecimento ainda não sedimentado, indagações e investigações em progresso" (SANTAELLA, 2005, p. 8). Ou seja, persiste em constante aperfeiçoamento e aprofundamento por parte dos seus estudiosos, que ao longo dos anos, agregaram conceitos e correntes filosóficas ao estudo da significação do discurso, podendo ser este um gesto, um texto, uma imagem, um som ou qualquer forma de linguagem.

Desta forma, este artigo destina-se a analisar o anúncio da Mitsubishi Pajero Full tendo como base o princípio da semiótica e a sua importância para a in- 
terpretação e percepção da mensagem publicitária. Tal estudo será referenciado os teóricos, Algirdas Julien Greimas (1973), Charles Pierce (2010), Roland Barthes (1990) e Martine Joly (1996) para perceber por meio da semiótica as relações sígnicas e a produção de sentido engendrada na mensagem publicitária.

\section{PRINCÍPIO DA SEMIÓTICA}

Os semióticos têm como base a semiologia, a ciência que estuda a linguagem verbal, originalmente propagada por Ferdinand Saussure em seu Curso de Linguística Geral no fim do século XIX, que evidenciado por Algirdas Julien Greimas em Semântica Estrutural (1973), enfatiza o poder de significação no mundo e destaca a importância dela para as ciências humanas. Neste estudo Greimas (1973) citado por Fiorin (1999) identificou, também, a ausência de uma ciência específica para o estudo da significação em sua época e sugere a criação de uma "semântica linguística, que se ocuparia da análise da significação, tal como é fornecida pelo código da língua” (FIORIN, 1999, p. 3).

A esse conceito é importante frisar que as denominações sobre linguagem não podem ser restritas apenas à língua, uma vez que esta atua sobre várias formas de linguagem. Portanto o objeto de estudo da semiologia é a língua, idioma falado pelas pessoas de determinada nação ou etnia, língua pátria, podendo ser verbal (fala) ou não verbal (escrita), e vem a ser apenas uma das formas de linguagem. Já a semiótica se encarrega de estudar todas as formas de se comunicar (SANTAELLA, 2005).

Partindo pelo princípio das formas de comunicação seja ela sonora, imagética, gestual, escrita, um fenômeno da natureza, entre várias outras, e tendo como conceito de linguagem como todo e qualquer sistema produtor de sentido, é importante perceber como o homem interpreta esses sistemas comunicativos que estão a sua volta. Parte dos estudos sobre as
Embora seja de extrema importância a análise dos discursos publicitário, este estudo não tem a pretensão de obter uma interpretação única e precisa sobre o anúncio analisado, mas sim, de poder contribuir para os estudos acadêmicos e para a dinâmica da semiótica na comunicação.

maneiras de percepção foram originados por Charles Pierce (2010) considerado como um dos principais semióticos e autor da semiótica moderna.

Peirce (2010) criou o princípio da fenomenologia, uma quase ciência que estuda os modos como o ser humano apreende qualquer coisa pela mente, tendo como base três ciências normativas (aquelas que estudam normas e valores) divididas através da estética, a ética e a lógica ou semiótica. A estética foca no que é admirável, no que sensibiliza, guia os sentimentos e atrai. A ética define os valores e normas de conduta, e a lógica estuda o pensamento, o raciocínio com base na estética e na ética, uma vez que Pierce (2010) argumenta que não há pensamentos sem signos.

A partir desta ciência normativa, Pierce (2010) dividiu a lógica em três ramos: a gramática especulativa (aquela que rege o estudo e classificação acerca dos tipos de signos), a lógica crítica aquela que, como define Santaella (2002, p.3), "estuda os tipos de inferências, raciocínios ou argumentos que se estruturam através do signo", e a retórica especulativa ou metodêutica que são os métodos de pesquisa.

A esse princípio da lógica, a semiótica Pierceana se preocupa com a percepção e interpretação do mundo ao redor dos indivíduos, e nesse caminho da percepção à interpretação. Para Pierce (2010) existem três etapas, ou categorias, como os fenômenos aparecem à consciência, chamadas de primeiridade, secundidade e terceiridade. 
A primeiridade se dá basicamente pela percepção primária, pelo reconhecimento do que é apresentado, do que é percebido, é a sensação pura daquele momento presente, daquele instante. A secundidade traz o que aquele signo representa, o seu significado, sua existência e materialização. Já a terceiridade é o pensamento intelectual, direcionado para o repertório que os indivíduos possuem com o universo, para as relações que têm com o mundo ao redor e a partir daí, interpretam o signo.

A essa divisão, Santaella (2005, p. 42) enfatiza que "não se deve entender essas categorias como entidades mentais, mas como modos de operação do pensamento-signo". Estes níveis de percepção são importantes para perceber como interpreta-se o que está em volta e por consequência as mensagens verbais e visuais.

Já o estudo dos signos, fica a cargo da Gramática Especulativa que estuda o signo e a sua natureza, classificando-o com base nas suas propriedades de representação, naquilo a que se refere e no efeito que vem a causar na mente do interpretante. "Pela qualidade, tudo pode ser signo, pela existência, tudo é signo, e pela lei, tudo deve ser signo" (SANTAELLA, 2002, p. 12).

Para esclarecer o significado de qualquer palavra, temos que recorrer a uma outra palavra que, em alguns traços, possa substituir a anterior. (1983: p 21). Logo, signo é tudo aquilo que gera uma representação mental (SANTAELLA, 2005, p. 21).

Neste contexto, Santaella (2005) argumenta que quanto à relação consigo mesmo, o signo pode expressar qualidade, indicar existência ou uma lei. Quando representa uma qualidade, remetendo ao seu significado através das associações feitas pelo intérprete em cima de uma qualidade, é chamado de quali-signo, exemplo: a cor vermelha é utilizada para chamar atenção, advertir um risco ou algo emergencial. Quando indica existência, ocupando lugar no tempo e espaço, interagindo e indicando outros signos existentes, é chamado de sin-signo, tendo como exemplo a fumaça, que indica que ali há fogo. Já quando representam por meio de uma lei, são chamados de legi-signo, como a queda de um corpo é regida pela lei da gravidade.

Se abordado a partir da referencialidade, ou seja, da relação do signo com o seu objeto, o signo poderá ser um ícone, índice ou símbolo (BARDARI, 2011). 0 aspecto icônico apresenta uma referencialidade aberta, onde os ícones têm um grau de semelhança com qualidades de algum objeto (DALFORNO, 2012), quanto ao aspecto indicial, Dalforno (2012) define que o índice faz uma referência direta e ambígua ao seu objeto, observando as marcas, traços e aspectos factuais.

\section{SEMIÓTICA NA PUBLICIDADE}

Dentre os vários campos de atuação da semiótica, como na linguística e no cinema, a publicidade também se faz presente. Ela surgiu com a necessidade do mercado de divulgação dos seus produtos, e começou a ser veiculada por meio das mídias sociais, a exemplo da mídia impressa (jornais, folhetos, cartazes), radiofônica e televisiva (SANTAELLA, 2002).

O uso de imagens nos discursos publicitários é presente e fundamental na tática de persuasão e se- dução, já que os arranjos estéticos são contempláveis, admiráveis e atraentes, e a publicidade visa enaltecer as qualidades daquilo que propaga para estimular o consumo, utilizando os elementos visuais para atingir esse objetivo (SOUZA; SANTARELLI, 2008). Para obter primeiramente uma definição de imagem, Martine Joly (1996, p.14) em sua obra Introdução a análise da Imagem defende que "uma imagem seria um objeto segundo com relação a outro que ela representaria de acordo com certas leis particulares". A partir des- 
sa definição, Joly (1996) aproxima a interpretação da imagem com os conceitos semióticos, na medida em que a esfera visual é uma das várias formas de linguagem coincidindo com a definição de signo, podendo a imagem ser um signo:

\begin{abstract}
[...] em publicidade, a significação da imagem é, certamente, intencional: são certos atributos do produto que formam a priori os significados da mensagem publicitária, e estes significados devem ser transmitidos tão claramente quando possível; se a imagem contém signos, teremos certeza que, em publicidade, esses signos são plenos, formados com vistas a uma melhor leitura: a mensagem publicitária é franca, ou pelo menos enfática (BARTHES, 1990 apud SOUZA, SANTARELLI, 2008, p. 4).
\end{abstract}

Para transmitir a mensagem, o discurso publicitário faz uso de técnicas que tendem a convencer o receptor de um querer-poder-fazer em relação ao que é apresentado, despertando no leitor uma necessidade que até então não era percebida, e aguçando a busca do mesmo pelo consumo do produto.

Esta indução é gerada por uma relação de identificação do consumidor com o produto, feita pelo enunciatário por meio de estudos sobre seu público alvo, seja enaltecendo as qualidades do produto ou serviço, por testemunho de terceiros, por associações com famosos ou estilos de vida almejados, por criar uma sensação de credibilidade na marca, ou até mesmo com uma função apelativa, com verbos no imperativo. Em muitos casos esta persuasão encontra-se implícita na mensagem publicitária, cabendo utilizar os estudos semióticos para não só entender as conotações e estruturas da mensagem formulada, como também, perceber a produção de sentido evidenciada no ato publicitário.

As imagens são dotadas de uma gama vasta de significações, visto que, se utilizadas em determinado contexto, conotam outro significado, a exemplo das metáforas, que nada mais são do que elementos utilizados fora do seu significado original, mas que remetem a outro por similaridade (SANTAELLA, 2002).
Nos anúncios e propagandas, elas são utilizadas para qualificar o produto referente, em muitos casos fazendo alusão a outro elemento.

Na publicidade as imagens nem sempre estão sozinhas, algumas peças publicitárias são substanciadas por meio da utilização da mensagem verbal, já que muitas vezes a imagem por si só não consegue transmitir de forma precisa a informação, dando margem a erros de interpretação em relação à esperada pelo anunciante. Para esse processo de significação da mensagem publicitária Barthes (1990) apud Souza \& Santarelli (2008) discriminou duas funções: a de ancoragem e a de revezamento. Na primeira, a imagem só consegue ser interpretada da maneira esperada pelo anunciante, por meio da mensagem linguística que vai atuar como apoio à imagem, reforçando o conceito da mensagem conotada. Já na segunda, a imagem sozinha dá margem a várias interpretações, fica vaga, e a mensagem linguística entra servindo como parte fundamental para chegar à mensagem conotada, respectivamente.

Afinal, como dito anteriormente, uma imagem pode conotar vários significados a depender do contexto em que esteja inserida, cabe à mensagem linguística situar o leitor e orientá-lo na sua interpretação.

O discurso publicitário é um produto cultural com foco na venda de produtos ou serviços, se espelhando na cultura e na sociedade que o produz e para a qual se dirige, criando um processo de identificação entre o público alvo e a mensagem do anúncio, tonando claro os aspectos e sistemas de valores daquele meio social (BAGGIO, 2003, p. 4), e é com base na sua cultura que o indivíduo faz a série de associações, chegando a uma interpretação.

Sendo assim, é necessário analisar a mensagem publicitária em seu contexto verbal e visual para não só visualizar os níveis de significação e produção de sentidos inseridos, mas verificar se a mensagem elaborada irá projetar o seu objetivo 
final (o ato da compra e identificação pelo consumidor). Desta forma, no mundo das marcas e empresas multinacionais, é preciso rever as campanhas globais antes de inseri-las em determinadas sociedades para não haver uma dissociação do sentido original, a fim de evitar a má interpretação, agressão à cultura local e rejeição da marca, produto ou serviço naquele meio social.

\section{ANÁLISE SEMIÓTICA DO ANÚNCIO MITSUBISHI PAJERO FULL}

A análise a seguir trata do anúncio da empresa Mitsubishi, publicado na revista Veja (Ed. 2277), que se refere ao veículo Pajero Full $4 \times 4$ exposto na figura 1 . A escolha de tal anúncio se deu pelo impacto causado por meio dos elementos visuais do mesmo, como fotos, cores e símbolos utilizados e dispostos, ainda que com auxílio de pouco texto, para transmitir a mensagem de uma forma pouco convencional em relação aos demais anúncios do mesmo segmento, sem exaltar as qualidades do produto de maneira explícita e direta, apelando para termos simbólicos e recursos predominantemente visuais.
A peça publicitária apresenta ao leitor a imagem de uma mulher trajando um vestido longo, vermelho e esvoaçado, joias, salto alto e maquiagem elegantes, montada em um rinoceronte; no canto inferior esquerdo, a figura do carro em si, e no canto inferior direito, a marca da empresa. Estes elementos, segundo a análise dos tipos de mensagem proposta por Barthes (1990) apud Souza e Santarelli (2008) representam o nível denotativo (icônico). Neste, “a mensagem denotada é a representação pura das imagens apresentando os objetos reais da cena" (SOUZA; SANTARELLI, 2008, p. 136).

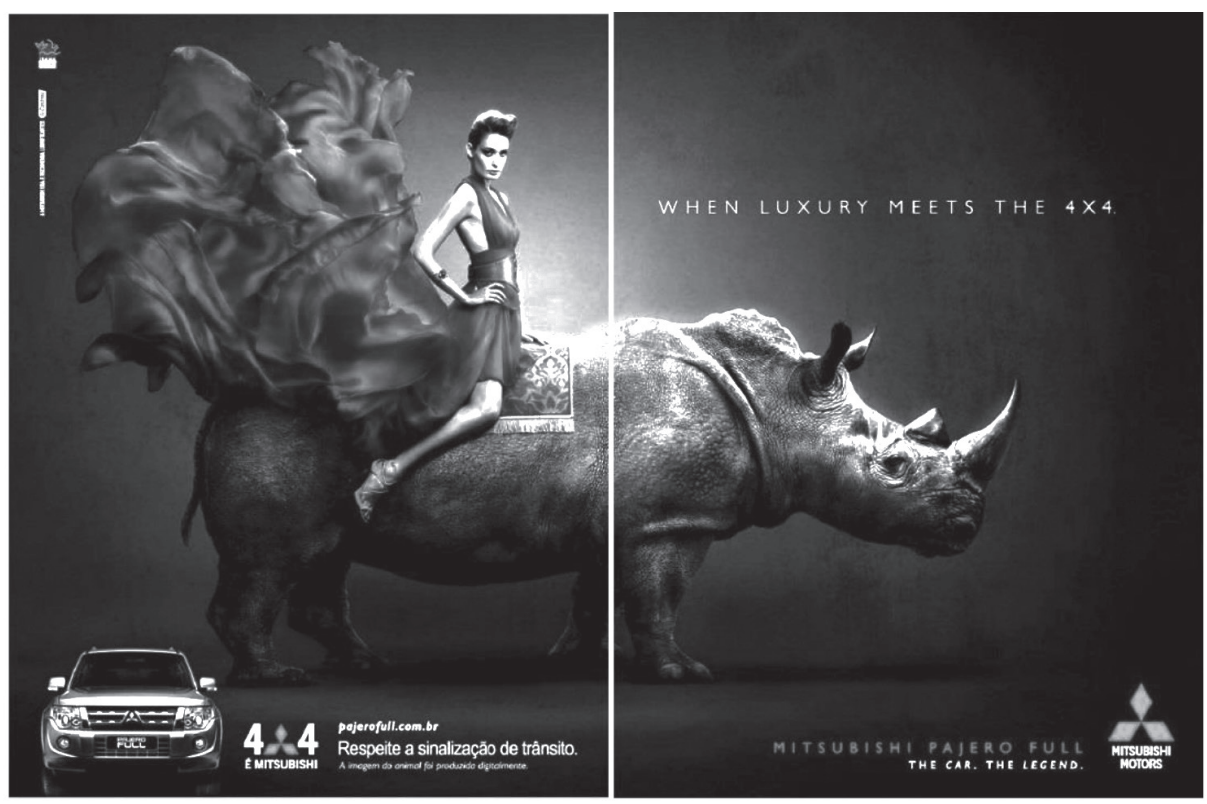

Fonte: Veiculado na Revista Veja (ed. 2277). 
Ao lado da imagem principal, há o texto "When luxury meets the $4 \times 4$ " " $Q$ Quando o luxo encontra 0 $4 \times 4$ "). Na parte inferior do anúncio, os textos " $4 \times 4$ é Mitsubishi", "Mitsubishi Pajero Full. The car. The legend." ("Mitsubishi Pajero Full. O carro. A lenda."). Estes compõem a mensagem linguística, que "tem a tarefa de ajudar na compreensão das imagens e pode exercer duas funções: a de ancoragem e a de revezamento" (SOUZA; SANTARELLI, 2008, p. 136). No caso do anúncio em análise, a mensagem linguística exerce função de ancoragem, pois esta "fornece uma explicação da imagem" (SOUZA; SANTARELLI, 2008, p. 136), além da associação e interpretação direta dos signos do anúncio, o texto reforça e confirma tal interpretação, tornando-a mais precisa para o leitor.

A mensagem conotada (simbólica) atribui os valores dos componentes das imagens ao veículo ao qual $o$ anúncio se refere: $A$ força e a potência de um veículo modelo $4 \times 4$ representadas pelo rinoceronte, a elegância e o luxo representados pela modelo, a junção dos dois em um único produto perceptível pela junção física de ambos na imagem, a mensagem verbal e a singela aparição do carro no canto do anúncio.

Esta propaganda tem o foco na união de duas ideias contrárias, na dualidade entre o luxo e a força reforçadas por meio dos "signos linguísticos" (JOLY, 1996). Esta relação de características opostas que se concentra em um único produto é expressa pelo texto "Quando o luxo encontra o 4x4", e representada pela modelo montada no animal, dando a ele um ponto de vista positivo em relação às suas qualidades e funções, o que é indicado pelo texto " 0 carro. A lenda”, o que dá um ar supremo e lendário ao veículo. Apesar do aspecto atemporal da imagem, e de não ter qualquer tipo de referência ao tempo físico, o tempo da narrativa se dá no presente, no momento descrito pelo texto em que "o luxo encontra o 4x4". O tempo no presente é algo comum no segmento publicitário, como define Trindade e Barbosa (2006, p. 8):
Na publicidade [...] há, propositalmente pela intencionalidade deste tipo de gênero discursivo, uma ideia de presente muito forte, pois as mensagens publicitárias indicam que a hora do comercial ou de leitura do anúncio é a hora oportuna de você conhecer e pensar em comprar o produto.

Também nota-se o aspecto de anterioridade e posterioridade da narrativa, quando o anúncio propõe que o carro apresentado surge após a fusão citada anteriormente. Neste sentido é importante referenciar a análise do percurso gerativo de sentido proposta por Greimas (1973) apud Fiorin (1999), que divide a mensagem em três níveis: fundamental, narrativo e discursivo. 0 nível fundamental "compreende a(s) categoria(s) semântica(s) que ordena(m), de maneira mais geral, os diferentes conteúdos do texto" (FIORIN, 1999, p. 5). 0 anúncio expõe de forma clara e simples as características contrárias do produto: luxo x potência, elegância $x$ força, tecnológico $x$ robusto; representadas na metáfora da imagem principal, onde há a modelo: elegante e delicada; e o rinoceronte: animal selvagem forte e robusto. Este corresponde ao seu nível fundamental.

Já no nível narrativo ocorre a transformação de estado, como define Fiorin (1999, p. 7) "A transformação é, por conseguinte, a mudança da relação entre sujeito e objeto". No anúncio, essa mudança de estado é percebida no texto "Quando o luxo encontra o 4x4", tendo como estado inicial carros "simples e comuns", no entanto, após essa transformação, há a fusão do luxuoso e do potente, tornando nítido o surgimento de um novo objeto no estado final da narrativa.

Quanto ao nível discursivo, "é aquele em que se revestem as estruturas narrativas abstratas" (FIORIN, 1999, p. 9). Após a transformação, há o surgimento de um carro inédito que une características que antes estavam segregadas. Percebe-se então que, no estado inicial da narrativa, existiam carros com apenas parte das características que foram somadas no novo, sendo esses apenas luxuosos ou apenas veículos com tração nas quatro rodas, e que por isso, o produto se torna inédito e revolucionário. 
Associada a esses elementos, a descrição do produto é feita, de uma forma geral, por todos os elementos do anúncio: verbal e visual. Já a predicação fica a cargo da imagem principal e do texto no canto inferior direito "O carro. A lenda", que enaltecem as qualidades do carro. A avaliação pode ser vista no texto "Se beber, não dirija”, na parte inferior do anúncio, e a persuasão está principalmente na imagem principal, pelo impacto das cores, dos signos expostos nela, a sua relação com o texto e a interpretação que o consumidor faz do anúncio como um todo.

O consumidor, através de tal interpretação, se sente atraído e deseja ter um carro lendário, luxuoso e potente, mas ao mesmo tempo o anúncio cria uma segmentação de público, tornando evidente a possibilidade de possuir o veículo acessível somente àqueles que possuem boas condições financeiras.

A escolha dos signos presentes no anúncio foi de suma importância para transmitir a mensagem, já que o mesmo conta com recursos predominantemente visuais. Sendo assim é importante analisar os signos plásticos composto na mensagem verbal divididos em forma, cor, enquadramento, entre outros elementos propostos por Joly (1996) quando analisada a imagem. 0 novo significado que cada um dos signos visuais recebem se dá pelo contexto no qual estão inseridos. A mulher bem vestida, com vestido vermelho (cor que representa a sedução e o luxo), remetendo a luxúria evidenciado pela angulação centralizada do anúncio e pelas representações gráficas. 0 consumidor interpreta, através da imagem, o conceito da elegância, luxo e poder enfatizados pelos signos icônicos Joly (1996). Já o animal escolhido, o rinoceronte, em que a modelo está montada, concede ao leitor o significado de força, robustez e potência e principalmente a singularidade do produto.

A junção dos dois elementos em uma imagem só passa o significado de soma de valores. Neste momento se dá o processo de significação, e este "não se trata de relacionar um objeto a um conceito, mas sim de um termo a uma 'imagem acústica”" (GENTIL, 2006, p.2), sendo esta "a representação natural da palavra, como facto virtual da língua. [...] A marca psíquica desse som" (SAUSSURE, 1916 apud GENTIL, 2006). Quando feita a leitura do texto "Quando a luxúria encontra o 4×4", o leitor automaticamente remete à imagem da modelo as características da luxúria e ao rinoceronte as características do $4 \times 4$, fazendo destas as imagens acústicas dos termos, aos quais o anúncio concebe seus próprios conceitos. Há também a alusão do símbolo da marca ao " $x$ " do termo " $4 \times 4$ " no escrito " $4 \times 4$ é Mitsubishi", na parte inferior do anúncio. Se utilizando da forma da marca, o anúncio a insere no termo, transmitindo a sensação de credibilidade e qualidade, por representar que a marca é pioneira e confiável quando se trata de veículos $4 \times 4$.

É necessário ressaltar que na mensagem linguística é exposta a segmentação de público, notável em vários pontos do anúncio. 0 uso de um idioma diferente da língua-mãe (o inglês) no texto requer um conhecimento prévio de tal língua para melhor interpretação por parte do leitor, ainda que a parte textual se utilize de cognatos (luxury - luxo; car - carro; legend - lenda) e que a imagem, mesmo isolada, tenha um bom poder de compreensão.

Há também a forte menção de valor, reforçado pela imagem. Devido a isso, e por se tratar de um veículo luxuoso, potente e com todos os recursos de design e tecnologia, o consumidor sabe que o mesmo custa caro, mesmo não estando explícito no anúncio seu valor de mercado exato. Isso traz ao consumidor a possibilidade de constatação ou elevação do seu status social, pois utilizar um objeto (no caso deste, um veículo) caro, retrata uma boa e confortável condição financeira. Esta postura de pertencimento, exposta na estrutura narrativa faz com que o consumidor tenha não só um produto, mas uma ferramenta oponente, poderosa, referenciado por meio da mensagem linguística, icônica e plástica como um produto inovador, revolucionário e lendário. 


\section{CONSIDERAÇÕES FINAIS}

A partir desta breve análise circunstanciada pelas teorias dos semióticos Pierce, Barthes, Joly e Greimas, é possível perceber como a produção de sentido na mensagem publicitária é evidenciada e como a elaboração textual e visual podem afetar o enunciatário de forma a persuadir e provocar efeitos de significação em um simples ato de venda. Todos os elementos dispostos num anúncio são dotados de significação, sejam estes referentes à sua essência real ou figu-

\section{REFERÊNCIAS}

BAGIO, Adriana Túlio. 0 espetáculo semiótico da publicidade que não diz seu nome: aspectos da temática homossexual na publicidade brasileira (2003). Disponível em:<http://www.slideshare.net/adribaggio/o-espetculo-semitico-da-publicidade-que-no-diz-seu-nome-aspectos-da-temtica-homossexual-na-publicidade-brasileira>. Acesso em: 29 jun. 2013.

BARDARI, Sérsi. Semiótica (2011). Disponível em <http:// sersibardari.com.br/wp-content/uploads/2011/03/Semi\%C3\%B3tica.pdf>. Acesso em: 20 jun. 2013.

DALFORNO, Andrea. Semiótica - Conceitos de signo (2012). Disponível em <http://www.slideshare.net/ andreadalforno/semitica-conceitos-de-signo>. Acesso em: 20 jun. 2013.

FIORIN, José Luiz (1999). Sendas e Veredas da Semiótica Narrativae Discursiva.Disponívelem:<http://www.scielo.br/scielo.php?pid=S010244501999000100009\&script=sci_abstract\&tlng=p>. Acesso em: 20 jul. 2013.

JOLY, Martine. Introdução à Análise da Imagem. São Paulo: Papirus, 1996. rada, compõem uma teia de associações na mente do leitor, e juntos tecem uma comunicação. Tal disposição dos elementos deve ser estudada a fim de estabelecer uma coerência no anúncio publicitário, sendo necessário recorrer à semiótica e seus estudos sobre sistemas produtores de sentido e percurso de interpretação, obtendo-se então uma vasta gama de signos e representações para poder construir uma mensagem.
GENTIL, Ana Catarina (2006). 0 Signo: Significado e Significante. Disponível em: <http://aquele.do.sapo. $\mathrm{pt} / \mathrm{fbaul} / 3941$ significSignificantXX.pdf>. Acesso em: 15 jun. 2013.

NICOLAU, Marcos; ABATH, Daniel; LARANJEIRA, Paulo C.; MOSCOSO Társila; MARINHO, Thiago; NICOLAU, Vítor. (2010) Comunicação e Semiótica: visão geral e introdutória à Semiótica de Peirce.

Disponível em: <http://www.insite.pro.br/2010/Agosto/semiotica_peirce_nicolau.pdf>. Acesso em: 22 jul. 2013

PEIRCE, Charles Sanders. Semiótica. 4. ed. São Paulo: Editora Perspectiva, 2010.

SANTAELLA, Lúcia. 0 que é semiótica. São Paulo: Editora Brasiliense, 2005.

SANTAELLA, Lúcia. Semiótica aplicada. São Paulo: Cengage Learning, 2002.

SOUZA, Sandra Maria Ribeiro de; SANTARELLI, Christiane Paula Godinho ( 2008) Contribuições para uma 
história da análise da imagem no anúncio publicitário. Disponível em: <http://www.portcom.intercom. org.br/revistas/index.php/revistaintercom/article/ viewArticle/198>. Acesso em: 10 jul. 2013.
TRINDADE, Eneus; BARBOSA, Ivan Santo (2006). Reflexões Sobre os Tempos da Enunciação e do Enunciado na Publicidade. Disponível em: <http://www. intercom.org.br/papers/nacionais/2006/resumos/ R1171-1.pdf>. Acesso em: 30 jun. 2013. 